\title{
Job Search Behavior of Employed Managers
}

\author{
Robert D. Bretz, Jr., John W. Boudreau, and Timothy A. Judge \\ Center for Advanced Human Resource Studies \\ School of Industrial and Labor Relations \\ Cornell University \\ Ithaca, NY 14853-3901
}

Working Paper \#93-17

Running Head: MANAGERIAL JOB SEARCH

This paper has not undergone formal review or approval of the faculty of the ILR School. It is intended to make results of Center research, conferences, and projects available to others interested in human resource management in preliminary form to encourage discussion and suggestions. 


\begin{abstract}
Job search typically has been thought of as an antecedent to voluntary turnover or job choice behavior. This study extends the existing literature by proposing a model of the job search process and examining the job search behavior of employed managers. Managers were initially surveyed about their job search activity over the past year. Approximately one year later, the same managers were surveyed to assess whether they had changed jobs since the initial survey, and the circumstances surrounding the job change. This survey data was matched with job, organizational, and personal information contained in the data base of a large executive search firm. Results suggest that dissatisfaction with different aspects of the organization and job were more strongly related to job search than were perceptions of greener pastures. Moreover, although some job search activity does facilitate turnover, a considerable amount of search does not lead to turnover. Thus, it appears that search serves many purposes. Implications of managerial job search on organizations are discussed.
\end{abstract}


Job Search Behavior of Employed Managers

Job search has played an important role in the theoretical development and empirical examination of job choice and voluntary turnover. Considerable research attention has been dedicated to developing theoretical models of the job choice process and to accumulating empirical data about how people generate alternatives and make job choices (Schwab, Rynes, \& Aldag, 1987; Soelberg, 1967; Vroom, 1964). Job choice models, however, typically presume that the decision to search already has been made, and attempt to delineate an "optimal stopping point, " or the point at which search is discontinued and a job choice made (Lee \& Mitchell, 1994; Schwab et al., 1987). This focus has produced valuable insights regarding the determinants of job choices, but has not directly contributed to our understanding of the search behaviors that precede the choices.

Likewise, research on voluntary turnover traditionally has embedded job search intentions within the construct of withdrawal cognitions, suggesting that job search behavior results from the same factors that lead to tumover (Hom, Caranikas-Walker, Prussia, \& Griffeth, 1992). However, some research reveals that job search is not simply a precursor to turnover and that at times the two processes may be inversely related (Hom \& Griffith, 1991). Hom et al. (1992) demonstrated that the temporal relation between intention to search and intention to quit was ambiguous, and that turnover intentions explained only about half the variance in search intentions. Moreover, the best-fitting structural equation model they examined contained a nonsignificant link between search intention and actual turnover (Hom et al., 1992; Hom, Griffeth, \& Sellaro, 1984).

Thus, job search, job choice, and voluntary turnover appear to be related but distinct concepts, and although choice and tumover have received considerable research attention, job Property of MARTIN P. CATHERWOOD LIBRARY

NEW YORK STATE SCHOOL

INDUSTRIAL AND LABOR REIATIOMS 
search has not been as thoroughly studied. The current study extends the existing literature by proposing a model of the job search process and examining job search behavior of employed managers. We began this study with the presumption that employed managers engage in job search for a variety of reasons, and that this search behavior affects individuals and organizations even when it does not result in job choice or turnover.

For example, people engage in job search to establish networks of influential contacts in their industry or niche (Lucht, 1991). Job search also is used as a means of leveraging improved employment conditions in one's current organization (Lazear, 1986). In fact, internal promotion policies make this strategy more likely because salaries typically are determined by job evaluation structures which capture internal relations between jobs, rather than by prevailing market rates for the abilities incumbents possess (Segal, 1986). Therefore, signalling that one is sought after at "market rate" might be used to increase one's salary. Thus, those with without serious intentions to leave the organization, or to actively choose among other alternatives, may engage in job search to convince others that the market values their contributions at a level that justifies better employment arrangements.

Altematively, consistent with equity theory, job search may convince oneself that the current position (and associated rewards) are attractive relative to existing alternatives (e.g., Blau, 1964). This would explain the positive relation between search and retention uncovered by Hom and Griffeth (1991).

Thus, job search is an important research topic for several reasons. First, it remains an empirical question whether the correlates of job search and turnover are similar or distinct. Moreover, although the job choice literature has been informative regarding the search activity of the unemployed (Devine \& Kiefer, 1991; Schwab et al., 1987), we know 
much less about how employed individuals search for alternatives, or the personal and organizational implications that follow. This study extends the current job choice and voluntary turnover literatures and examines these questions by proposing and testing a model which directly positions job search behavior of employed managers as a dependent variable of interest.

Second, search behavior, whether it results in turnover or not, is costly because it absorbs time and energy that might be put to other uses (March \& Simon, 1958), and may engender psychological processes that induce withdrawal behavior and reduce commitment to the current job and organization (Locke, 1976). These costs might be especially relevant at higher organizational levels because the consequences of non-performance in the upper echelons of organizations are likely to be greater than at lower organizational levels (Hunter, Schmidt, \& Judiesch, 1990). Moreover, little currently is known about the search behaviors of managers and executives, and what is known is based on small samples from single organizations (e.g., Gaertner \& Nollen, 1992). Thus, better understanding search and turnover behavior among managers and executives across organizations would seem to have practical implications for virtually any organization.

\section{Model Development}

Early attempts to understand the job search process drew heavily from Neoclassical economics. These models imposed constraints of perfectly competitive environments where the searcher had full knowledge of alternatives and potential outcomes, and presumed that job search reflected attempts to maximize utility (Devine \& Kiefer, 1991; Lippman \& McCall, 1979). This was problematic on both conceptual and empirical grounds. Conceptually, if the environment permitted full knowledge of all alternatives, it would not be 
necessary to expend effort and time to acquire information about labor market alternatives. Empirically, research has demonstrated that labor markets typically do not approach ideals of perfect competition, and that people are largely unaware of employment alternatives (Segal, 1986; Schwab et al., 1987).

More recent theories of job search have relaxed the rationality assumption by recognizing that job search is costly and that people must exert effort to exchange market information with potential employers (Kormendi, 1979; March \& Simon, 1958). However, the focus of this literature has been on what outcomes satisfy implicit utility constraints (what people search for), not on the search behavior itself (Lee \& Mitchell, 1994). That is, recent models of "job search" are really models of "choice" because they have focused on the evaluation of alternatives, not the generation of alternatives (Schwab et al., 1987).

The literature examining the antecedents and consequences of search intensity appears to be the most focused examination of actual job search behaviors. Search intensity has been measured using indices such as number of employers contacted, number of information sources used, or hours per week spent searching (Schwab et al., 1987). This literature has provided considerable insight about job search behavior under specific conditions. For example, it appears that financial need leads to higher levels of search intensity (see Schwab et al., 1987, for a review). Other evidence suggests that self esteem also is positively related to search intensity (Ellis \& Taylor, 1983), and that people are more likely to search if their expectancy of finding an acceptable job is high (Harrell \& Stahl, 1986; Rynes \& Lawler, 1983). Research also has shown that search intensity is positively related to shorter unemployment durations (Barron \& Gilly, 1979; Barron \& Mellow, 1981; Dyer, 1973; Kanfer \& Hulin, 1985; Sheppard \& Belitsky, 1966). Two potential limitations of this 
literature, however, are that it has presumed that the purpose of search is simply to inform choice, and it has relied on unemployed samples where financial need may be more salient than in employed samples. Thus, non-choice motives for engaging in search may have been obscured (Devine \& Kiefer, 1991; Lee \& Mitchell, 1994). The question of how and why employed managers search has remained unexamined.

Therefore, job search is defined here as the specific behaviors through which effort and time are expended to acquire information about labor market alternatives, irrespective of the motives for, or consequences of, the information gathering activity (Blau, 1993; Schwab et al., 1987). The research model (Figure 1) proposes that among employed managers, environmental, work-related, and individual factors influence the motivation to engage in job search by affecting the perceived costs and benefits of doing so, and that opportunity (as expressed by human capital acquisitions) moderates the relation between search and separation. The search construct reflects actual search activity. Although previous research has examined search and separation intentions (Hom et al., 1992), search activity has been studied much less frequently. Yet, search activity is important because it is conceptually closer to many of the withdrawal behaviors that search presumably relates to, and because, among managers, it can be a highly visible activity that may prompt an organizational response.

\section{Insert Figure 1 Here}

Motivation to search reflects two general processes endogenous to both the economic and the psychological perspectives of job choice and turnover. First, there is evidence of a 
"push" process, which reflects the degree to which current work or life situations cause sufficient discomfort or dissatisfaction to warrant generation and evaluation of alternatives (Lee \& Mitchell, 1994). Prior theory and research suggest relations between withdrawal behavior and work attitude variables such as job satisfaction, job stress, perceived internal promotional opportunities, and pay level (Lee \& Mitchell, 1994; Mobley, Griffeth, Hand, \& Meglino, 1979). Unacceptable levels of these variables likely "push" individuals to consider alternatives because the benefit of doing so presumably offsets the costs.

However, search also can be motivated by a "pull" process which reflects the costs or difficulties of searching in relation to the probability of finding a new position. From this perspective, the level of search activity will be positively related to the income an individual believes his/her knowledge, skills and abilities (KSAs) can command in the market (Lippman \& McCall, 1979), and inversely related to the perceived costs of the search (Kormendi, 1979). For employed individuals search costs may be low because the loss in utility from not securing an acceptable alternative is offset by the benefits of the current position (Hall, Lippman \& McCall, 1979). The labor economic literature suggests that the costs of searching may vary with personal factors, such as an individual's network of contacts or the degree to which the individual's visibility is likely to position one as a target of external recruitment activities (Devine \& Kiefer, 1991). Thus, variables such as the success of the individual's organization, industry, public trading of the employing organization's stock, and the manager's historical record of success may be relevant.

In addition, individual preferences for allocating time between work and non-work activities also may affect the degree to which the current work relationship is desirable, and thus the perceived costs and benefits of searching. Classical labor economic theory suggests 
an optimal allocation of time between work and leisure such that the marginal utility of leisure divided by the marginal utility of income equals the wage rate (Burdett, 1979). For the unemployed, excess leisure is converted into job search activity to increase the probability of finding a job that offers sufficient income to maximize expected utility of lifetime consumption (Danforth, 1979; Devine \& Kiefer, 1991). For the employed, however, insufficient leisure may prompt search. That is, people are assumed to work only to the point where the value of leisure becomes greater than the income earned. Therefore, if the desire for leisure exceeds the amount of leisure available, one might be motivated to search for alternatives that permit more desirable allocation of time. Extending this concept to include desire for work family balance suggests that people also will be more likely to search for alternatives if they desire more work-family balance than is possible under the current arrangement (Greenhaus \& Beutell, 1985).

We propose (see Figure 1) that motivation to search reflects the accumulated work experiences of the manager in his/her current job and organization, as well as the perceived relative attractiveness of alternatives and the costs and benefits of searching. Much previous research has confirmed that variables such as job satisfaction, job stress, perceived organizational attractiveness, and perceived alternative opportunities are related to separation decisions, and suggests that such variables operate at least in part by motivating intentions to search for alternative opportunities (Hom et al., 1992; Lee \& Mitchell, 1994; Mobley et al., 1979). There is less research on the relation between search intentions and search activity (Kopelman, Rovenpor, \& Millsap, 1992), but it seems plausible to propose a positive relation between variables that motivate search intentions and the search behavior itself. On these bases we hypothesized: 
H1: The overall relation between the vector of motivation variables and search will be significant, with the influence of each variable in the direction specified in Figure 1.

Kopelman et al. (1992) provide evidence that search activity and separations are closely related, such that those who search more intensively are more likely to separate. Our model distinguishes between motivational influences and search behavior as they relate to separation. Little previous research has directly compared the effects of these two variables. Instead, previous research has relied on self-reported "search intentions" to reflect the search process that may mediate the relation between motivation and separation. Following Kopelman et al. (1992), we expect that the relation between search and separation will be stronger than the direct relation between motivation and separation. Moreover, we expect that search will largely mediate the relation between motivation and separation. Though the "scripts" proposed by Loe and Mitchell (1994) undoubtedly exist, our study deals with upperlevel managers who generally have experience and resources available to deliberate about their job changes. Thus, we expect to see few examples of the impulsive quits that might characterize other groups (Lee \& Mitchell, 1994).

Similarly, we expect that the relation between motivation and search will be stronger than the relation between search and separation. Search activity, while certainly not costless, requires fewer resources and causes less disruption than does separation. Indeed, it seems quite likely that many managers in this sample may have developed "habits" of search behavior, such that they search quite frequently, even when they have little intention of actually leaving their organization (Lee \& Mitchell, 1994). Such search activity is likely to be driven by both the "push" factors of dissatisfaction with the present situation, but perhaps 
even more by the "pull" factors that reflect the ease with which search activity can be undertaken, or the degree to which alternative opportunities are likely to become apparent through search. Thus, search activity is seen as more than a precursor of separation. We propose that search may be an ongoing process that is determined as much by the ease with which information can be obtained as it is by the motivation to actually leave. Managers may find information about their alternative opportunities useful even when they have no intention of leaving. One obvious use for such information is to demonstrate their marketability, as a way to enhance their position in their present organization.

On these bases we hypothesized:

H2: The relation between search and separation will be positive and significant, even controlling for possible direct effects of the motivation variables.

H3: The relation between search and motivation will be stronger than the relation between search and separation.

In our model, opportunity reflects the individual's marketability and capacity to actually leave the current organization. Human capital and labor market theories (e.g., Becker, 1965; March \& Simon, 1958) suggest that some individuals will be more marketable than others, based on differences in acquired human capital. That is, those with more human capital will have more alternative employment opportunities than others. While separation can occur even in the absence of alternative employment opportunities (e.g., Lee \& Mitchell, 1994), separations are undoubtedly influenced by the identification of alternatives.

The role of opportunity remains ambiguous in existing job choice and turnover models. An inverse relation between opportunity and search can be justified on the premise that those with greater marketability will require less search behavior, either to locate 
suitable alternatives, or to satisfy their information needs. Simply put, more qualified individuals may have to search less to reveal their positioning in the market. Search costs are lower for such individuals because their qualifications allow information acquisition with less exertion (Lippman \& McCall, 1979).

A positive relation between opportunity and separation also is possible. Recently, Lee and Mitchell (1994) proposed that separations may occur without the need for an individual to engage in extensive deliberations or search activity. A "shock to the system" may be enough to trigger sufficient motivation to leave, especially when the individual has a readilyavailable script that positions separation as a feasible and appropriate reaction (e.g., a small organization merges with a very large organization, the individual has established strong values against working for large organizations, and the individual has successfully left other organizations under the same circumstances). Under these conditions, individuals with more human capital are likely to have more attractive alternatives and may separate with little or no search involved.

Labor market search theories (e.g., Becker, 1965; Doeringer \& Piore, 1970; Lippman \& McCall, 1979) suggest that the more relevant human capital one possesses, the more attractive one is to employers. Therefore, organizations with employment opportunities have a greater incentive to seek out prospective employees who are well-qualified than those who are not as well-qualified. In the same sense that individual search activity may be modelled by a cost-benefit comparison (Lippman \& McCall, 1979), so may employers' communication activity. Therefore, individuals with greater human capital are more likely to receive information about alternatives, and thus more likely to separate even with limited search activity. 
Finally, it also is possible that opportunity moderates the relation between search and separation. This effect is consistent with most traditional turnover models (Hom et al., 1992), as well as with theories of human capital acquisition (Lee \& Mitchell, 1994). Individuals with greater opportunities are more likely to discover attractive alternatives through their search, and thus are more likely to separate at a given level of search activity. Therefore, we examined three hypotheses regarding the effects of opportunity:

H4: Opportunity (as expressed by higher levels of human capital) will be significantly negatively related to job search.

H5: Opportunity (as expressed by higher levels of human capital) will be significantly positively related to separation.

H6: Opportunity (as expressed by higher levels of human capital) will moderate the relation between job search and separation.

\section{Method}

\section{Subjects}

Subjects were 3,581 (a 50\% random sample) of the managers contained in the data base of Paul R. Ray \& Company, the fifth largest executive search firm in the United States. Ninety-seven percent of the sample were White, $93 \%$ were male, and $91 \%$ were married. Forty-nine percent had one or more children. Average age of the managers was 45.5 years. Virtually all members of the sample were U.S. citizens (95\%) working in the U.S. at the time of the study (98\%). The average manager worked 56 hours per week, spent 5 hours per week caring for dependents, and devoted 13 hours per week to leisure activities. Total compensation averaged $\$ 134,746$ per year. The average manager had spent 3 years in his/her current position, and occupied a job 2 levels below that of the CEO. On average, 
managers had earned 6.4 promotions in their career, and their last promotion occurred 3.2 years ago. Forty-five percent possessed undergraduate degrees, $46 \%$ had earned masters degrees, and $9 \%$ had doctorates.

This search firm operates on a retainer basis, its clients being the companies that are searching for employees, not the managers themselves. Thus, the firm does not accept applications or resumes from individuals searching for positions. Rather, it develops lists of potential candidates only in direct response to a client's search assignment for a specific position. The identification process includes identifying top corporate officers through publicly-filed information such as $10-\mathrm{K}$ reports, proxy materials, etc. This is supplemented by examining industry publications, directories, and professional association mailing lists (e.g., the Young Presidents' Association). In some cases, this is further supplemented through direct calls to companies, requesting information on the names of their top managers. Calls to managers already in the data base are sometimes used to identify other promising prospects. This search firm serves clients of all sizes, in all industries and regions in the U.S. In recent years, the most frequent industry categories for search requests have been financial services (20\%) and health care (20\%). The data base, however, contains a more general sample than these two areas suggest, because it has been developed over many years in response to searches across industries. To ensure that the data base remains current, the firm sends requests for address changes twice per year. When requests are returned as undeliverable the individual is deleted from the file. When requests are returned with a new address, the data base is updated. Virtually all of the managers in the data base are either currently employed, or were employed within the last year. 
The sample appears to lie somewhere between the "average" U.S. manger and the "corporate elite." Respondents are somewhat different from U.S. Department of Labor data reported for all executive, administrative and managerial positions and from Business Week's characterization of the corporate elite in the 1000 most valuable companies. Department of Labor data suggest that the population of managers is $90 \%$ White, $59 \%$ male, and earns an average annual salary of $\$ 46,400$ (U.S. Department of Labor, 1993). In contrast, Business Week's corporate elite is, on average 56.3 years old and $98 \%$ male with an average annual salary over $\$ 878,000$ (Business Week, 1992). It appears, therefore, that our sample consists of more males and earns considerably more than the representative population of managers would suggest. It also appears that the sample is younger and earns considerably less than the corporate elite.

\section{Procedure}

In July 1992 subjects received a questionnaire assessing the degree to which they had engaged in job search behaviors over the last year, historical career information, and work perceptions and attitudes. A cover letter from the chief executive officer of the search firm, and a stamped return envelope addressed to the authors, accompanied each survey. Each survey contained a control number so that returned surveys could be matched with information contained in the search firm's data base. Participants were informed that their responses would be matched with the data in the company's data base but that all responses were strictly confidential. Of the surveys that were mailed, $39 \%(1,388)$ were completed and returned. This response rate compares favorably with other mail survey research (Dillman, 1978). We specified a MANOVA model which simultaneously considered the interrelated effects of all variables in order to determine if respondents were representative of 
the larger sample. In no case did any variable in the search firm's data base (marital status, number of children, evaluation of quality, citizenship, age, employer size defined in terms of sales volume or number of employees, total compensation, international work experience, job tenure, or education) differ significantly at the .05 level between respondents and nonrespondents. Thus, it appears that our sample was representative of the larger population.

In October of 1993, a follow-up survey was sent to all individuals who had responded to the original questionnaire. Each survey contained a control number so that it could be matched to previous responses and data base information. Of the 1,388 follow-up surveys sent, 660 (48\%) were completed and returned. The second survey assessed whether the respondent had changed jobs since the last survey, the circumstances surrounding the job change, relative status of current and past positions, and level of job satisfaction.

\section{Measures}

Job search activity. Job search was measured using the Job Search Behavioral Index (JSBI; Kopelman et al., 1992). The JSBI asks respondents to indicate (yes vs. no) whether they have engaged in ten different job search activities over the past year, specifically whether the individual had read a book about getting a new job, revised his/her resume, read position listings in professional journals or newspapers, talked to colleagues, friends or relatives about getting a new job, sent copies of resumes to prospective employers, initiated contact with an executive search firm, gone to a job interview, and made telephone inquires to prospective employers. We modified some of the language to be consistent with the higher level jobs sought by our sample. For example we changed "read the classified/help wanted advertisements in the newspaper" to "read the position listings in professional 
journals or newspapers." One item from the original JSBI (actively sought a transfer to another job within the organization) was eliminated from our scale because seeking an internal transfer seemed conceptually different from external search. Additionally, in the reliability analysis this variable demonstrated a negative item-total correlation. Thus, for conceptual and empirical reasons, it was deleted from the scale. The internal consistency estimate (K-R 20) for the remaining nine dichotomous items was .86 .

Motivation variables. Data about the industry in which the manager was currently employed, whether the employing organization's stock was publicly traded, and whether the employing organization was a Fortune 500 firm, were obtained from the search firm's data base.

Job satisfaction was measured with a composite of 3 single-item measures that were placed in different parts of the first survey. These included the Gallup Poll measure of job satisfaction (where respondents indicate whether they are satisfied with their job by responding "Yes" or "No"), the non-graphic version of the G. M. Faces Scale, and an adapted version of the Fordyce Percent Time Happy Item, where the individual reported the percent time they are satisfied with their job on average. These items all have demonstrated favorable psychometric properties relative to faceted measures of job satisfaction (Diener, 1984; Judge \& Hulin, 1993; Scarpello \& Campbell, 1983). Because the 3 items were measured on different scales, they were standardized (using Z-scores) prior to computation of the composite measure. The coefficient alpha internal consistency estimate for this threeitem composite measure was .85 .

Job stress was measured using selected items from existing stress scales. Although several existing scales display acceptable psychometric properties (see Matteson \& 
Ivancevich, 1987), they were not suitable for the present application for two reasons. First, most existing measures are extremely long (60 to 117 items), and representatives of the search firm who had had substantial survey experience with this sample indicated that such length would severely restrict the response rate. Second, existing scales tend to include many items that are not appropriate for a high-level managerial sample (e.g., questions about quality of supervision). In response, from existing stress scales (Job Stress Index, Sandman, 1992; Michigan Diagnostic Survey, French \& Kahn, 1962; Stress Diagnostic Survey, Matteson \& Ivancevich, 1987) we chose 16 items that seemed most relevant to our sample, and included them on the first survey. To be consistent with the existing form of the questions, respondents were asked to indicate the degree to which the items produced stress at work for them $(1=$ produces no stress, $5=$ produces a great deal of stress $)$. Although space limitations prohibit listing each item, the complete scale is available upon request. Coefficient alpha for this new sixteen-item job stress scale was .84 .

Ambition was conceptualized as the degree to which the executive desired additional upward mobility. It was assessed with a question on the first survey that asked "How many levels do you want to move up from your present position in your current organization?" (5-

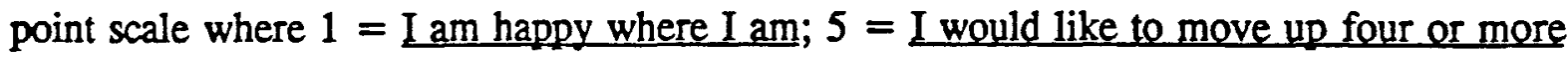
levels). The second item assessed the perceived job ceiling by asking "How many levels do you think you could move up in your current organization?" (5-point scale where $1=\mathrm{I}$ could not move up at all; $5=$ I could move up four or more levels). Finally, because the current job level likely affects both desire and opportunity to move up, one item asked "How many levels below CEO is your current position?" 
Perceived job alternatives was measured by a survey question that asked "Give your best estimate of your present alternative employment opportunities" (5-point scale where $1=$ no alternatives; 5 = many alternatives). Perceptions of employment opportunities seemed appropriate because perceptions drive the decision processes which are observable as specific job search behaviors (Blau, 1993; Soelberg, 1967).

Compensation level was obtained from the search firm's data base. Other variables were derived from questions on the first survey. Ascension rate measured the average number of promotions per year. This was determined by dividing career length (in years) into the total number of promotions received. Perceived organizational success was assessed by a question that asked "How successful would you say your organization has been in reaching its strategic goals during the last two years?" Respondents were asked to give a percentage, with $0 \%$ indicating that the organization had had no success and $100 \%$ indicating complete success in meeting its goals. Because perceptions motivate behavior, regardless of their accuracy, perceptions of organizational success are conceptually better indicators of motivation to search than are actual measures of organizational success. Moreover, the desire to preserve confidentiality prevented the search firm from releasing company names, which might have facilitated the use of more objective measures.

Attitudes toward leisure and work-family balance were considered to be individual factors that might influence motivation to search. Attitudes toward leisure were assessed by two questions on the first survey. Respondents were asked to indicate the number of hours per week actually spent on leisure, and number of hours desired to spend on leisure.

To measure the degree to which organizations have policies in place to accommodate work and family issues, 5 questions on the first survey asked the manager to rate (using a 5- 
point scale where $1=$ none; 5 = a very large amount) the degree to which (1) my organization provides programs to assist in balancing demands of dual-career couples; (2) my organization provides programs to assist in balancing demands of families with children and/or elderly family members; (3) my organization stresses the importance of family, leisure, and health; (4) my organization provides opportunities for managers to take part-time or temporary assignments; (5) my organization supports employee involvement in community service. Coefficient alpha for this scale was .75. To measure the degree of work-family balance desired, managers again responded to the five work-family items (using a 5-point

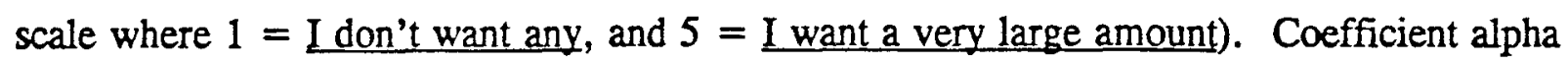
for this scale was .73 .

Opportunity variables. Data about education level was taken from the search firm's data base, and was coded 1 = bachelor's degree, 2 = master's degree, and $3=$ doctorate degree. Education quality was assessed using the Gourman (1993) rankings of educational institution quality applied to the institution granting the respondents' highest degree. The Gourman Report rates all U.S. degree-granting institutions on 18 quality dimensions and is frequently used as a measure of quality because it is the only guide to higher education that assigns numerical indicators of overall quality (Solmon, 1973).

Ratings of candidate quality were taken from the search firm's data base. When candidates are added to the data base, they are interviewed by a minimum of three Paul Ray \& Company associates who rate them (3-point scale where $3=$ low, $4=$ average, $5=$ high) on the following dimensions: (1) flexibility and adaptability; (2) proficiency in current job; and (3) appearance, stature and personal impact. The rating recorded in the data base represents the average rating provided by the company associates. Inter-rater reliabilities 
were not available. For this study, we combined the three ratings into an overall index of candidate quality. Coefficient alpha for the three-item scale was .62. Note, however, that because this rating represents a multi-rater consensus, coefficient alpha may be less informative.

Data about race (coded $1=$ white, $0=$ otherwise), gender (coded $1=$ male, $0=$ female), and age were acquired from the search firm's data base. Finally, job tenure was assessed by a question on the first survey.

Separation. Separation was assessed by a question on the second survey that asked whether respondents had left the position they had occupied at the time of the first survey. We also asked respondents to indicate the circumstances surrounding their job changes. Of the 660 second surveys retumed, $85(13 \%)$ indicated that they had voluntarily resigned to accept a position in a different organization.

\section{Results}

Correlations between the variables used in the analyses are presented in Table 1, and descriptive statistics are shown in Table 2. The pattern of correlations indicated generally low levels of association between the variables, thus facilitating multivariate analysis. The notable exceptions were the significant positive relation between search and separation, and the significant negative relations between search and perceived organizational success, total compensation, and job satisfaction. Separation, on the other hand, also was negatively related to these variables, but at a much lower level. The correlations also suggested a strong positive relation between hours of leisure desired and actual hours of leisure $(\underline{r}=$ $.80)$, and a strong positive relation between ambition and perceived job ceiling $(\Sigma=.58)$. 


\section{Hypothesis One}

Table 3 shows the regression results when job search activity is regressed on the vector of motivation variables. As hypothesized, the overall relation was significant $\underline{R}=$ $.52, \mathrm{E}=16.64, \mathrm{p}<.001)$. Among the motivation variables, the direction of influence was generally as predicted, although several variables failed to achieve significance. Consistent with the "push" theory, the significant negative relations observed for job satisfaction, compensation level, perceived organizational success, and organizational policies for facilitating work-family balance were most notable, as were the significant positive relations observed for ambition, and the desire for greater work-family balance. The significant positive coefficient on publicly traded employer, appears consistent with the "pull" theory. For the industry variables, effect coding (Darlington, 1990) was used, so the regression coefficients on the industry variables indicate the job search propensity of members in each industry, relative to the average across industries. That is, managers in the medical and health-related products industry engaged in more search than the average manager in this sample, while those in the manufacturing industry engaged in significantly less search. 
Hypotheses Two and Three

The relation between search and separation was positive and significant $(\underline{r}=.19, \mathrm{p}$ $<.001$; see Table 1). The distributional properties of the dichotomous separation variable, however, violate the assumptions of the Pearson product moment correlation, and thus suppress the magnitude of the true relationship. The polyserial correlation corrects the distributional properties of the dichotomous variable in much the same way as log-linear transformations of dichotomous dependent variables do in logistic regressions (Judge, 1993; Olsson, Drasgow, \& Dorans, 1982). Therefore, we computed the polyserial correlation between job search and separation $(r=.312, \mathrm{p}<.001)$.

To examine the relation between motivation and separation, we specified a logistic regression model with separation as the dichotomous dependent variable. Motivation significantly predicted separation (Chi-Square with $23 \mathrm{df}=39.99, \mathrm{p}<.05$ ). Consistent with "pull" theories, perceived employment opportunities $(B=.38, D<.05)$ and ascension rate $(\underline{B}=.51, \mathrm{p}<.05)$ were positively related to separation, while consistent with the "push" perspective, job satisfaction $(\underline{B}=-.13, \mathbb{D}<.05)$ was inversely related to separation. No other variables achieved significance. When the model was re-specified to include the job search index on the second step, there was a significant improvement in model fit (ChiSquare with $10 \mathrm{df}=10.56, \mathrm{D}<.001)$ and search $(\mathrm{B}=.20, \mathrm{p}<.01)$ became the most significant predictor in the equation. It appears, therefore, that $\mathrm{H} 2$ is supported.

Hypothesis three stated an expected stronger relation between motivation and search than between search and separation. Results suggest significant positive relations on both accounts [Multiple $\mathbb{R}$ (motivation, search) $=.52, \mathrm{~g}<.001$; polyserial $\mathrm{I}$ (search, separation) $=.31, \mathrm{p}<.001]$. The significance of the difference between these relationships was 
examined using Fisher's $\underline{I}$ to $\underline{\mathrm{Z}}$ transformation. Consistent with $\mathrm{H} 3$, the relation between motivation and search was significantly stronger than the relation between search and separation $(\mathrm{p}<.001)$.

\section{Hypothesis Four}

To test the relation between opportunity and search activity, job search was regressed on the vector of opportunity variables. A significant relation was noted, and the direction of influence for all the variables except age was negative. Thus, $\mathrm{H} 4$ received support. Job tenure was significantly inversely related to search, and women engaged in more search than did men. Full regression results are presented in Table 4.

Insert Table 4 Here

\section{Hypothesis Five}

To test the relation between opportunity and separation, we specified a logistic regression model that regressed separation on the vector of opportunity variables. The model significantly predicted separation (Chi-Square with $9 \mathrm{df}=17.78, \mathrm{p}<.05$ ), and with the exception of education quality and gender, the direction of influence was positive. Thus H5 received support. Complete model results are presented in Table 5.

\section{Insert Table 5 Here}




\section{Hypothesis Six}

To examine the degree to which opportunity moderated the relation between search and separation, we conceptualized a logistic regression model with separation regressed on search, the opportunity variables, and the interactions between search and each of the opportunity variables. While conceptually possible, this model is problematic due to the colinearity caused by the interaction of search with seven other variables (candidate rating, education level, education quality, job tenure, age, gender, race). Therefore, consistent with the approach used by Barrick and Mount (1993), in order to observe the effects of each search by opportunity interaction, we specified separate models with search and one of the opportunity variables entered on the first step, and the interaction term entered on the second step. Specifically, the following models were specified with separation as the dependent variable: (1) search, education level, and search by education level, (2) search, candidate rating, and search by candidate rating, (3) search, education quality, and search by education quality, (4) search, job tenure, job tenure squared, and search by job tenure, (5) search, age, age squared, and search by age, (6) search, race, and search by race, (7) search, gender, and search by gender.

In all of the models, search was significantly positively related to separation but the opportunity variable was not. Therefore, it appeared that controlling for search activity, the opportunity variables were having little effect. When the interaction terms were entered on the second step, in only two equations did the interactions achieve significance. Therefore, H6 received only partial support. The interaction with education level and the interaction with candidate rating were significantly related to separation but the others were not. The equations for education level and candidate rating are presented in Table 6. 


\section{Insert Table 6 Here}

The interaction between education level and search is plotted in Figure 2. The three lines plot the relation between search and the probability of turnover for three education levels; the mean level of education (1.72), one SD above the mean (2.33), and one SD below the mean (1.11). The values for Figure 2 were derived by using the logistic regression equations in Table 6, calculating the predicted value of the logistic function for each pair of search/education values, and transforming the logistic value to the corresponding probability (Hanuschek \& Jackson, 1977, pp. 187-190). Figure 2 reveals that increased search leads to an increased probability of leaving for all education levels, but that the effect of search on separation is inversely related to education level. The lower the education level, the greater the effect a unit change in search has on separation. The same procedure was used to examine the interaction between candidate rating and separation, producing similar results. Because both graphs were similar, only the graph for education is shown in Figure 2.

Insert Figure 2 Here

The results in Table 6 and Figure 2 indicate that higher levels of search increase the probability of turnover for all managers, but the effect is more pronounced for those with less human capital. That is, for those with lower qualifications, search makes a bigger difference in their probability of separation. This might be due to the fact that those with 
more human capital find alternative opportunities rather easily, or because those with less human capital must search harder to identify opportunities that are otherwise open only to more qualified managers.

\section{Discussion}

This study tried to fill the void between models of job choice which begin with the assumption that a decision to search already has been made (e.g., Schwab et al., 1987), and models of voluntary turnover which assume that job search activity is an intermediate step between job dissatisfaction and organizational exit, primarily engaged in to facilitate choice. We examined job search activity as a dependent variable, and attempted to explain how different motivational forces and opportunities affect job search and separation. This approach is useful because not all job search leads to turnover, but virtually all job search is costly (March \& Simon, 1958) and exerts its toll in the form of withdrawal behavior and lost productivity (Locke, 1976). At managerial job levels, the dysfunctional effects of these behaviors may be relatively large given the nature of the work involved and the time span of discretion allowed (Jaques, 1961). Therefore, understanding managerial job search activity has very practical implications for organizations operating in increasingly competitive environments.

The results provide general support for the hypothesized relations between motivation, job search, opportunity, and separation. We found that a vector of variables suggested by the voluntary turnover and labor market literatures was significantly related to job search activity, and that "push" factors were much more strongly linked to search than were "pull" factors. That is, dissatisfaction with different aspects of the organization and job was related to search, although perceptions of greener pastures were not. These results are consistent 
with many models of employee turnover that postulate dissatisfaction as a primary cause of turnover intentions that ultimately lead to organizational exit (Bannister \& Griffeth, 1986; Cotton \& Tuttle, 1986; Dalessio, Silverman, \& Schuck, 1986; Mobley, Horner, \& Hollingsworth, 1978).

We also observed a significant relation between search and separation after controlling for the effects of motivation. That is, consistent with the voluntary turnover models, some search clearly does relate to separation. However, the relation between search and motivation was stronger than the relation between search and separation, supporting our contention that search serves many purposes in addition to facilitating choice and separation. Thus, it would appear that through attention to the "push" factors, organizational policy setters have considerable influence over the search behavior of their managers.

Finally, we found that the opportunity variables were mostly inversely related to search but many were positively related to separation. Thus, it appears that less search activity is engaged in by the more marketable managers, but higher levels of separation can be expected among this elite group. This also was apparent in the significant interactions between education, candidate rating, and search in predicting separation.

The results suggest that future research is needed to further delineate why currently employed, "successful" people, engage in costly (from both personal and organizational perspectives) job search activity. Because a large portion of variance in job search activity remains unexplained, it would be useful to examine the effects of variables not included in the current study. One avenue to explore is the role of person-organization fit. Previous research has shown that perceptions of fit often strongly affect applicant decision processes (Bretz, Ash, \& Dreher, 1989; Bretz \& Judge, in press; Judge \& Bretz, 1992; Rynes, Bretz, 
\& Gerhart, 1991; Turban \& Keon, 1993). However, this research has focused on lower level managerial jobs (generally recent college graduates), and as such is not very informative about either the dimensionality of fit at managerial levels, or how managers might go about assessing fit. Because fit does seem to be important in many job search strategies, future examinations of managerial job search should consider how it affects decision making at this level.

Future research may reveal significant value from programmatic investments in retaining management talent. Our results suggest that the most marketable and highestperforming managers find alternative positions most easily when they search, but that their decision to search may be largely a function of job and organization variables, rather than market opportunities. Thus, it appears that organizations willing to invest in retention strategies providing greater rewards and recognition to their most valuable managers can retain those managers, even in the face of open market competition. Boudreau and Berger (1985) have shown that the value of human resource interventions often may depend more on the interventions' effects on retention patterns, than on simply reducing turnover rates. The key is systematically to retain those whose value is greater than the average value of those in the applicant pool. The present results suggest that programs aimed at increasing managerial satisfaction, compensation, and desired work-family balance may have significant positive long-run effects on the quality of managers retained. Future research should measure not only the investment costs of such programs, but their effects on managerial retention patterns, within a comprehensive cost-benefit framework. Such research may prove more informative than simply measuring program costs or retention patterns separately, and may thus have greater relevance for managerial decisions (Boudreau, 1991). 
There are limitations with this study that should be noted. The most prominent of these concerns common method bias. Although data were collected from an existing data base and two mail surveys, the majority of the data were generated from self-reports of work attitudes and working conditions. The longitudinal nature of the data collection process, the verifiable nature of some of the variables, and fact that not every variable was self-reported should help mitigate the problem. This is, however, clearly an area where future research could improve our understanding of managerial job search by using other data collection strategies that limit this potential threat to statistical conclusion validity.

Another area in which future research could make a substantial impact would be through less reliance on perceptual measures. For example, although we found that perceived organizational success was inversely related to search behavior, we cannot comment on the degree to which actual organizational performance affects managerial job search. It also would be interesting to collect information about actual upward-mobility opportunities the managers face, and specific organizational work-family policies. Collecting such data would allow examination of how organizational contingencies affect search behavior, and whether accurate perception of these contingencies is related to job search.

We also experienced some limitations due to measurement issues. Specifically, we did not measure some variables that might be related to search. For example we cannot comment on whether line or staff status, prior job search propensities, or the degree to which functional expertise (finance, marketing, human resources, etc.) affect search. Future research, therefore, should consider a broader set of organizational variables. Additionally, because existing measures of job satisfaction and job stress were not appropriate for our sample, we constructed abbreviated measures of these constructs. This makes comparisons 
with other samples difficult and limits our ability to comment on the generalizability of these results. Finally, future research designs that collect motivation information prior to job search information will build on this study through the ability to make causal inferences that we are unable to make.

On the positive side, the current study does provides a broader perspective than typically has been offered. Little research exists about search behavior in general, and prior research about managerial turnover has been limited to small samples and single organizations (e.g., Gaertner \& Nollen, 1992). In this regard, the current study adds significantly to our understanding of managerial job search because it assessed the job search activity of a large sample of high level managers employed across a broad spectrum of organizations and industries. The results, therefore, are likely to be very generalizable within the managerial population. 


\section{References}

Bannister, B.D., \& Griffeth, R.W. (1986). Applying a causal analytic framework to the Mobley, Horner, and Hollingsworth (1978) turnover model: A useful reexamination. Journal of Management, 12, 433-443.

Barrick, M.R., \& Mount, M.K. (1993). Autonomy as a moderator of the relationship between the Big Five personality dimensions and job performance. Journal of Applied Psychology, 78, 111-118.

Barron, J., \& Gilly, D.W. (1979). The effect of unemployment insurance on the search process. Industrial and Labor Relations Review, 32, 363-366.

Barron, J.M., \& Mellow, W. (1981). Changes in labor force status among the unemployed. Journal of Human Resources, 16, 427-441.

Becker, G.S. (1965). A theory of the allocation of time. Economic Journal, 75, 493-517. Blau, G. (1993). Further exploring the relationship between job search and voluntary turnover. Personnel Psychology, 46, 313-330.

Blau, T. (1964). Exchange and power in social life. New York: Wiley. Boudreau, J. W. (1991). Utility analysis for decisions in human resource management. In M. D. Dunnette \& L. M. Hough (Eds.) Handbook of Industrial and Organizational Psychology, (2nd ed.), Vol. 2. Palo Alto: Consulting Psychologists Press, pp. 621745.

Boudreau, J. W. \& Berger, C. J. (1985) Decision-theoretic utility analysis applied to employee separations and acquisitions. Journal of Applied Psychology, 70, 581-612.

Bretz, R.D., Ash, R.A., and Dreher, G.F. (1989). Do people make the place? An examination of the attraction-selection-attrition hypothesis. Personnel Psychology, $\underline{42}$ $561-581$. 
Bretz, R.D., and Judge, T.A. (in press). The role of human resource systems in job applicant decision processes. Journal of Management.

Burdett, K. (1979). Search, leisure and individual labor supply. In S.A. Lippman \& J.J. McCall (Eds.), Studies in the economics of search, 157-170. Amsterdam: NorthHolland.

Business Week. (1992, Oct 12). The corporate elite, 119-146.

Cotton, J.L., \& Tuttle, J.M. (1986). Employee turnover: A meta-analysis and review with implications for research. Academy of Management Review, 11, 55-70.

Dalessio, A., Silverman, W.H., \& Schuck, J.R. (1986). Paths to turnover: A re-analysis and review of existing data on the Mobley, Horner, and Hollingsworth turnover model. Human Relations, 39, 245-264.

Danforth, J.P. (1979). On the role of consumption and decreasing absolute risk aversion in the theory of job search. In S.A. Lippman \& J.J. McCall (Eds.), Studies in the economics of search, 109-132. Amsterdam: North-Holland.

Darlington, R.B. (1990). Regression and linear models. New York: McGraw-Hill. Devine, T.J., \& Kiefer, N.M. (1991). Empirical labor economics. New York: Oxford University Press.

Diener, E. (1984). Subjective well-being. Psychological Bulletin, 95, 542-575.

Dillman, D. A. (1978). Mail and telephone surveys: The total design method.

New York: Wiley.

Doeringer, P.B., \& Piore, M.J. (1970). Internal labor markets and manpower analysis. Lexington, MA: Heath.

Dyer, L. (1973). Job search success of middle-aged managers and engineers. Industrial and Labor Relations Review, 26, 969-979. 
Ellis, R., \& Taylor, S. (1983). Role of self-esteem within the job search process. Joumal of Applied Psychology, 68, 632-640.

French, J. R. P., \& Kahn, R. L. (1962). A programmatic approach to studying the industrial environment and mental health. Joumal of Social Issues, 18, 1-47.

Gaertner, K.N., \& Nollen, S.D. (1992). Tumover intentions and desire among executives. Human Relations, 45, 447-465.

Gourman, J. (1993). The Gourman report. Los Angeles: National Education Standards. Greenhaus, J.H., \& Beutell, N.J. (1985). Sources of conflict between work and family roles. Academy of Management Review, 10, 76-88.

Hall, J.R., Lippman, S.A., \& McCall, J.J. (1979). Expected utility maximizing job search. In S.A. Lippman \& J.J. McCall (Eds.), Studies in the economics of search, 133-156. Amsterdam: North-Holland.

Hanuschek, E.A. \& Jackson, J.E. (1977). Statistical Methods for Social Scientists. New York: Academic Press.

Harrell, A., \& Stahl, M. (1986). Additive information processing and the relationship between expectancy of success and motivational force. Academy of Management Journal, 22, 429-433.

Hom, P.W., Caranikas-Walker, F., Prussia, G.E., and Griffeth, R.W. (1992). A metaanalytic structural equations analysis of a model of employee turnover. Journal of Applied Psychology, 77, 890-909.

Hom, P.W., \& Griffeth, R.W. (1991). A structural equation model of the process of employee turnover: Cross-sectional and longitudinal tests. Joumal of Applied Psychology, 76, 350-366. 
Hom, P.W., Griffeth, R.W., \& Sellaro, C.L. (1984). The validity of Mobley's 1977 model of employee turnover. Organizational Behavior and Human Performance, 34, 141174.

Hunter, J.E., Schmidt, F.L., \& Judiesch, M.K. (1990). Individual differences in output variability as a function of job complexity. Joumal of Applied Psychology, 75, 2642.

Jaques, E. (1961). Equitable payment. New York: John Wiley \& Sons.

Judge, T.A. (1993). Does affective disposition moderate the relationship between job satisfaction and voluntary turnover? Joumal of Applied Psychology, 78, 395-401. Judge, T.A., \& Bretz, R.D. (1992). Effects of work values on job choice decisions. Joumal of Applied Psychology, 77, 261-271.

Judge, T.A., \& Hulin, C.L. (1993). Job satisfaction as a reflection of disposition: A multiple-source causal analysis. Organizational Behavior and Human Decision Processes, 56, 388-421.

Kanfer, R., \& Hulin, C. (1985). Individual differences in successful job searches following layoff. Personnel Psychology, 38, 835-847.

Kopelman, R., Rovenpor, J., \& Millsap, R. (1992). Rationale and construct validity evidence for the job search behavior index: Because intentions (and New Year's resolutions) often come to naught. Joumal of Vocational Behavior, 40, 269-287.

Kormendi, R.C. (1979). Dispersed transaction prices in a model of decentralized pure exchange. In S.A. Lippman \& J.J. McCall (Eds.), Studies in the economics of search, 53-82. Amsterdam: North-Holland.

Lazear, E.P. (1986). Raids and offer matching. In R.G. Ehrenberg (Ed.) Research in labor economics, (Vol 8), 141-165. Greenwich, CT: JAI Press. 
Lee, T.W., \& Mitchell, T.R. (1994). An alternative approach: The unfolding model of voluntary employee turnover. Academy of Management Review, 19, 51-89.

Lippman, S.A., \& McCall, J.J. (1979). Studies in the economics of search. Amsterdam: North-Holland.

Locke, E.A. (1976). The nature and causes of job satisfaction. In M.D. Dunnette (Ed.), Handbook of industrial and organizational psychology (pp. 1297-1350). Chicago: Rand McNally.

Lucht, J. (1991). Rites of passage at $\$ 100,000+$. Viceroy Press: New York.

March, J., \& Simon, H. (1958). Organizations. New York: John Wiley \& Sons, Inc.

Matteson, M. T., \& Ivancevich, J. M. (1987). Controlling work stress. San Francisco: Jossey-Bass.

Mobley, W.H., Griffith, R.W., Hand, H.H., \& Meglino, B.M. (1979). A review and conceptual analysis of the employee turnover process. Psychological Bulletin, 36, 493-522.

Mobley, W.H., Horner, S.O., \& Hollingsworth, A.T. (1978). An evaluation of precursors of hospital employee turnover. Joumal of Applied Psychology, 63, 408-414.

Olsson, U., Drasgow, F., \& Dorans, N.J. (1982). The polyserial correlation coefficient. Psychometrika, 41, 337-347.

Rynes, S.L., Bretz, R.D., and Gerhart B. (1991). The importance of recruitment in job choice: A different way of looking. Personnel Psychology, 44, 487-521.

Rynes, S.L., \& Lawler, S. (1983). A policy-capturing investigation of the role of expectancies in decisions to pursue job alternatives. Journal of Applied Psychology, 68, 620-631. 
Sandman, B. A. (1992). The measurement of job stress: Development of the Job Stress Index. In C. J. Cranny, P. C. Smith, \& E. F. Stone (Eds.), Job satisfaction: How workers feel about their jobs and how it affects their performance (pp. 241-254). New York: Lexington Books.

Scarpello, V., \& Campbell, J. P. (1983). Job satisfaction: Are all the parts there? Personnel Psychology, 36, 577-600.

Schwab, D.P., Rynes, S.L., \& Aldag, R.J. (1987). Theories and research on job search and choice. In K.M. Rowland and G.R. Ferris (Eds.), Research in Personnel and Human Resources Management (Vol. 5, pp. 129-166). Greenwich, CT: JAI Press.

Segal, M. (1986). Post-institutionalism in labor economics: The forties and fifties revisited. Industrial and Labor Relations Review, 39, 388-403.

Sheppard, J.L., \& Belitsky, A.H. (1966). The job hunt. Baltimore: Johns Hopkins Press. Soelberg, P.O. (1967). Unprogrammed decision making. Industrial Management Review, $8,19-29$.

U.S. Department of Labor. (1993). Employment and eamings, 40, 193-239. Bureau of Labor Statistics.

Vroom, V.H. (1964). Work and motivation. New York: Wiley. 


\section{Author Notes}

We thank Sharon Voros of Paul R. Ray \& Company for assistance with this study. We also thank Dan Cable, Tim Nolan and Meiyu Fang for assistance with data preparation. Finally, we thank the editor and three anonymous reviewers for helpful comments on an earlier version of this manuscript. 


\begin{tabular}{|c|c|c|c|c|c|c|c|c|c|c|c|c|c|c|c|c|c|c|c|c|c|c|}
\hline & 2 & 3 & 4 & 5 & 6 & 7 & 8 & 9 & 10 & 11 & 12 & 13 & 14 & 15 & 16 & 17 & 18 & 19 & 20 & 21 & 22 & 23 \\
\hline 1 & Search & -28 & -20 & 01 & 17 & 03 & 05 & -04 & -42 & 17 & 02 & 02 & 12 & -14 & -01 & 04 & 01 & -02 & -17 & -09 & -04 & -07 \\
\hline 2 & Separation -- & -07 & -02 & 02 & 06 & -03 & 10 & 07 & -14 & 08 & -04 & -01 & 01 & -07 & -02 & -05 & -01 & 02 & -10 & -09 & -10 & -01 \\
\hline 3 & Perceived org succ. & -- & 09 & -00 & -07 & -02 & -05 & 05 & 32 & -16 & -03 & 00 & -06 & 11 & 00 & 02 & -02 & -07 & 12 & 03 & 03 & 03 \\
\hline 4 & Log of Total Comp. & & - & -11 & -18 & -12 & 02 & 15 & 08 & -07 & 01 & 03 & -16 & -00 & -01 & 12 & 16 & 06 & 06 & 19 & 05 & 18 \\
\hline 5 & Perceived Job Celli & & & -- & 58 & 18 & 07 & 14 & 08 & -03 & -04 & -05 & 06 & 08 & -00 & 01 & -00 & -06 & -12 & -24 & -00 & 03 \\
\hline 7 & Current Job Level & & & & & -- & -04 & -02 & -09 & 05 & -01 & -02 & 07 & -00 & 01 & -00 & -04 & -07 & 00 & -09 & -01 & -05 \\
\hline 8 & Ascension Rate & & & & & & -- & 08 & -01 & -05 & 04 & 04 & 02 & 08 & -02 & 07 & 11 & -08 & -11 & -07 & -05 & 01 \\
\hline 9 & Perceived Job Alter & enativ & ves & & & & & -- & 16 & -09 & -02 & 01 & 01 & 14 & -07 & -03 & 10 & 01 & -09 & -19 & -01 & -01 \\
\hline 0 & Job Satisfaction & & & & & & & & -- & -29 & -07 & -05 & -04 & 27 & 04 & -03 & 05 & 02 & 04 & -01 & -04 & -01 \\
\hline 1 & Job stress & & & & & & & & & -- & 02 & -09 & 22 & -16 & -04 & 00 & -02 & 01 & -06 & -14 & -03 & -14 \\
\hline 2 & Hourg of Leigure De & esired & & & & & & & & & -- & 80 & 05 & 01 & 06 & -01 & -00 & -00 & 03 & 06 & -05 & -03 \\
\hline 3 & Actual Hours of Lei & Leure & & & & & & & & & & -- & -00 & 06 & 08 & 01 & -01 & 00 & 05 & 11 & -03 & 04 \\
\hline 4 & Desire for Work-Fam & nily $B$ & Balanc & & & & & & & & & & -- & 36 & -00 & -01 & -01 & 02 & -02 & -13 & -10 & -18 \\
\hline 6 & Fortune 500 Employe & & & & & & & & & & & & & & -- & 14 & 02 & 05 & 08 & 07 & 01 & 01 \\
\hline 7 & Publicly Traded Emp & ployer & & & & & & & & & & & & & & -- & 01 & 04 & 02 & 04 & -01 & 05 \\
\hline 8 & Candidate Rating & & & & & & & & & & & & & & & & -- & -04 & 01 & -04 & 01 & -04 \\
\hline 9 & Education Level & & & & & & & & & & & & & & & & & - & 02 & 11 & -02 & -03 \\
\hline 0 & Years of Job Tenure & & & & & & & & & & & & & & & & & & -- & 23 & 06 & 02 \\
\hline 1 & Age & & & & & & & & & & & & & & & & & & & -- & 13 & 19 \\
\hline 2 & Race (White) & & & & & & & & & & & & & & & & & & & & -- & 06 \\
\hline 3 & Gender (Male) & & & & & & & & & & & & & & & & & & & & & - \\
\hline
\end{tabular}

ote: Decimals omitted. Correlations greater than .07 are significant at $p<.01$; those greater than .09 are gignificant at $<.001$. Listwise deletion yielded sample size of 1025 for correlational analysis except for those with Separation (N = 513; orrelation with search significant $\mathbf{p}<.001$, correlation with Job satisfaction significant $\mathbf{p}<.01)$. Correlations with Education uality were omitted because listwise deletion yielded $N=104$. Industry variable correlations are omitted due to space onstraints, and are available upon request. 


\begin{tabular}{|c|c|c|c|c|c|}
\hline & Mean & stan. Dev. & Minimum & Maximum & $\mathbf{N}$ \\
\hline Search & 4.92 & 2.96 & 0 & 9 & 1354 \\
\hline Separation & .13 & .34 & 0 & 1 & 660 \\
\hline Perceived Organizational success & 65.67 & 26.10 & 0 & 100 & 1387 \\
\hline Log of Total Compensation & 11.66 & .52 & 7.60 & 14.40 & 1383 \\
\hline Perceived Job Celling & 1.00 & .94 & 0 & 4 & 1325 \\
\hline Ambition & 1.30 & .98 & 0 & 4 & 1316 \\
\hline Current Job Level & 2.14 & 3.05 & 0 & 6 & 1388 \\
\hline Ascension Rate & .46 & .65 & 0 & 10 & 1233 \\
\hline Perceived Employment Alternatives & 3.76 & .85 & 1 & 5 & 1381 \\
\hline Job satiofaction & .02 & 2.63 & -5.32 & 3.74 & 1279 \\
\hline Job stress & 40.69 & 9.07 & 16 & 75 & 1373 \\
\hline Hours of Lelsure Desired & 19.10 & 11.11 & 0 & 106 & 1388 \\
\hline Actual Hours of Leisure & 12.76 & 9.59 & $\mathbf{0}$ & 76 & 1388 \\
\hline Desire for Work-Family Balance & 13.92 & 3.82 & 5 & 25 & 1274 \\
\hline Organization's Work-Family Policies & 9.48 & 3.79 & 5 & 25 & 1269 \\
\hline Fortune 500 Employer & .00 & .06 & 0 & 1 & 1383 \\
\hline Publicly Traded Employer & .12 & .33 & $\mathbf{0}$ & 1 & 1383 \\
\hline Candidate Rating & 13.30 & 1.07 & 9 & 15 & 1388 \\
\hline Education Level & 1.72 & .61 & 0 & 3 & 1388 \\
\hline Education quality & 67.72 & 45.91 & 0 & 294 & 277 \\
\hline Yeare of Job Tenure & 3.09 & 2.53 & 0 & 25 & 1383 \\
\hline Age & 45.47 & 7.32 & 25 & 73 & 1383 \\
\hline Race (White) & .97 & .16 & 0 & 1 & 1366 \\
\hline Gender (Male) & .93 & .26 & 0 & 1 & 1362 \\
\hline
\end{tabular}


Table 3

Regression Results of Motivation Variables on Search Activity

\begin{tabular}{|c|c|c|c|c|}
\hline & B & $\mathbf{S E}$ & Beta & $\mathbf{F}$ \\
\hline Perceived Org. Success & -.015 & .003 & -.133 & $21.38 * * \star$ \\
\hline Total Compensation (ln) & -.718 & .165 & -.126 & $18.91 * \star \star$ \\
\hline Perceived Job Ceiling & -.147 & .107 & -.047 & 1.90 \\
\hline Ambition & .373 & .108 & .121 & $11.98 * \star \star$ \\
\hline Current Job Level & -.039 & .027 & -.041 & 2.11 \\
\hline Ascension Rate & .114 & .139 & .023 & 0.67 \\
\hline Perceived Job Alternatives & .181 & .099 & .052 & 3.31 \\
\hline Job Satisfaction & -.364 & .035 & -.323 & $108.01 * \star \star$ \\
\hline Job stress & .008 & .010 & .025 & 0.70 \\
\hline Hours of Leisure Desired & -.022 & .011 & -.082 & 3.30 \\
\hline Actual hours of Leisure & .027 & .014 & .085 & 3.43 \\
\hline Desife for $W-F$ Balance & .078 & .024 & .100 & $10.35 * *$ \\
\hline Org. W-F Balance Policies & -.059 & .025 & -.074 & $5.51 *$ \\
\hline Fortune 500 Employer & .094 & 1.51 & .002 & 0.00 \\
\hline Publicly Traded Employer & .572 & .243 & .065 & $5.52 \star$ \\
\hline Consumer Products Ind. & -.572 & .371 & -.058 & 2.38 \\
\hline Food Service Ind. & -.327 & .199 & -.050 & 2.71 \\
\hline High Technology Ind. & .074 & .170 & .013 & 0.19 \\
\hline Manufacturing Ind. & -.780 & .335 & -.083 & $5.42 *$ \\
\hline Entertainment Ind. & -.237 & .285 & -.028 & 0.69 \\
\hline Not-For-Profit Ind. & -.175 & .214 & -.025 & 0.67 \\
\hline Oil and Gas Ind. & -.102 & .283 & -.012 & 0.13 \\
\hline Medical Services Ind. & .617 & .208 & .093 & $8.79 * \star$ \\
\hline constant & 12.41 & 2.02 & & $37.88 * *$ \\
\hline Multiple R & .52 & & & \\
\hline $\mathrm{R}^{2}$ & .28 & & & \\
\hline$A d j \cdot R^{2}$ & .26 & & & \\
\hline
\end{tabular}

Note. $\underline{\mathbf{N}}=1021 . *=\mathrm{p}<.05, * \star=\mathrm{p}<.01, * \star * \mathrm{p}<.001$ 
Table 4

Regression Results of Opportunity Variables on Search Activity

\begin{tabular}{|c|c|c|c|c|}
\hline & B & SE & Beta & $\mathbf{F}$ \\
\hline Candidate Rating & -.016 & .074 & -.006 & 0.05 \\
\hline Education Level & -.063 & .130 & -.013 & 0.23 \\
\hline Years of Job Tenure & -.297 & .067 & -.253 & 19.72 * \\
\hline Job Tenure squared & .006 & .005 & .074 & 1.71 \\
\hline Age & .156 & .101 & .384 & 2.38 \\
\hline Age squared & -.002 & .001 & -.407 & 2.69 \\
\hline Race (White) & -.019 & .496 & -.001 & 0.00 \\
\hline Gender (Male) & -.702 & .317 & -.061 & $4.89 *$ \\
\hline Constant & 3.41 & 2.55 & & 1.79 \\
\hline Multiple $R$ & .22 & & & \\
\hline $\mathbf{R}^{2}$ & .05 & & & \\
\hline Adj. $R^{2}$ & .04 & & & \\
\hline
\end{tabular}

Note. $\underline{N}=1336$. Education quality was omitted because with it included listiws deletion yielded $\underline{N}=270$, and when it was added no variables reached significano $\star=\mathrm{P}<.05, \star \star=\mathrm{P}<.01, \star \star \star \mathrm{P}<.001$. 


\section{Table 5}

Logistic Regression Results of Opportunity Variables on Seperation

\begin{tabular}{lcc} 
& $\begin{array}{c}\text { Maximum Likelihood } \\
\text { Estimate }\end{array}$ & SE \\
\hline Candidate Rating & .084 & .110 \\
Education Level & .088 & .194 \\
Education Quality & -.121 & .385 \\
Years of Job Tenure & .022 & .198 \\
Job Tenure Squared & -.023 & .027 \\
Age & .340 & .206 \\
Age Squared & -.004 & .002 \\
Race (White) & $-1.162 *$ & .574 \\
Gender (Male) & .166 & .507 \\
Constant & -8.986 & 4.845 \\
& & \\
Chi-square (9 df, n $=649)$ & $17.78 *$ & \\
-2 Log Likelihood & 478.53 & \\
Goodnegs of Fit & 633.42 &
\end{tabular}

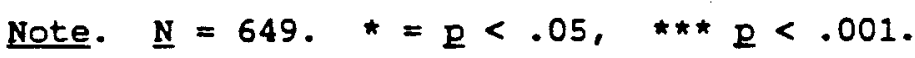


Table 6

Logistic Regression Results of Search and Opportunity Interaction on Seperation

Maximum Likelihood

Eatimate

SE

Education Level

Education Level

Job search

Job Search X Education

.863

.480

$.461 * \star \star$

.140

Constant

$-.140 *$

.073

$-4.622 \star \star \star$

.951

Chi-square ( $1 \mathrm{df}$, $\underline{\mathrm{n}}=649$ )

$3.68 *$

-2 Log Likelihood

473.96

coodness of Fit

649.28

Candiate Rating

$\begin{array}{lcr}\text { Candidate Rating } & .626 * & .282 \\ \text { Job search } & 1.397 * * & .042 \\ \text { Job search x Rating } & -.088 * & 3.883 \\ \text { Constant } & -11.505 * * & \\ \text { Chi-Square (l df, } \underline{n}=649) & 4.53 * \\ \text {-2 Log Likelihood } & 472.59 \\ \text { Goodnegs of Fit } & 634.72\end{array}$

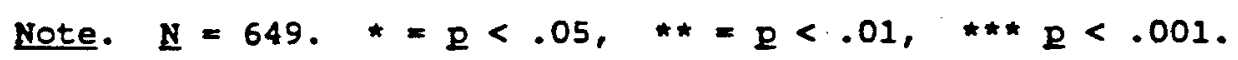




\section{Figure Captions}

Figure 1. A model of job search among employed managers.

Figure 2. Interaction between search and education level predicting separation. 


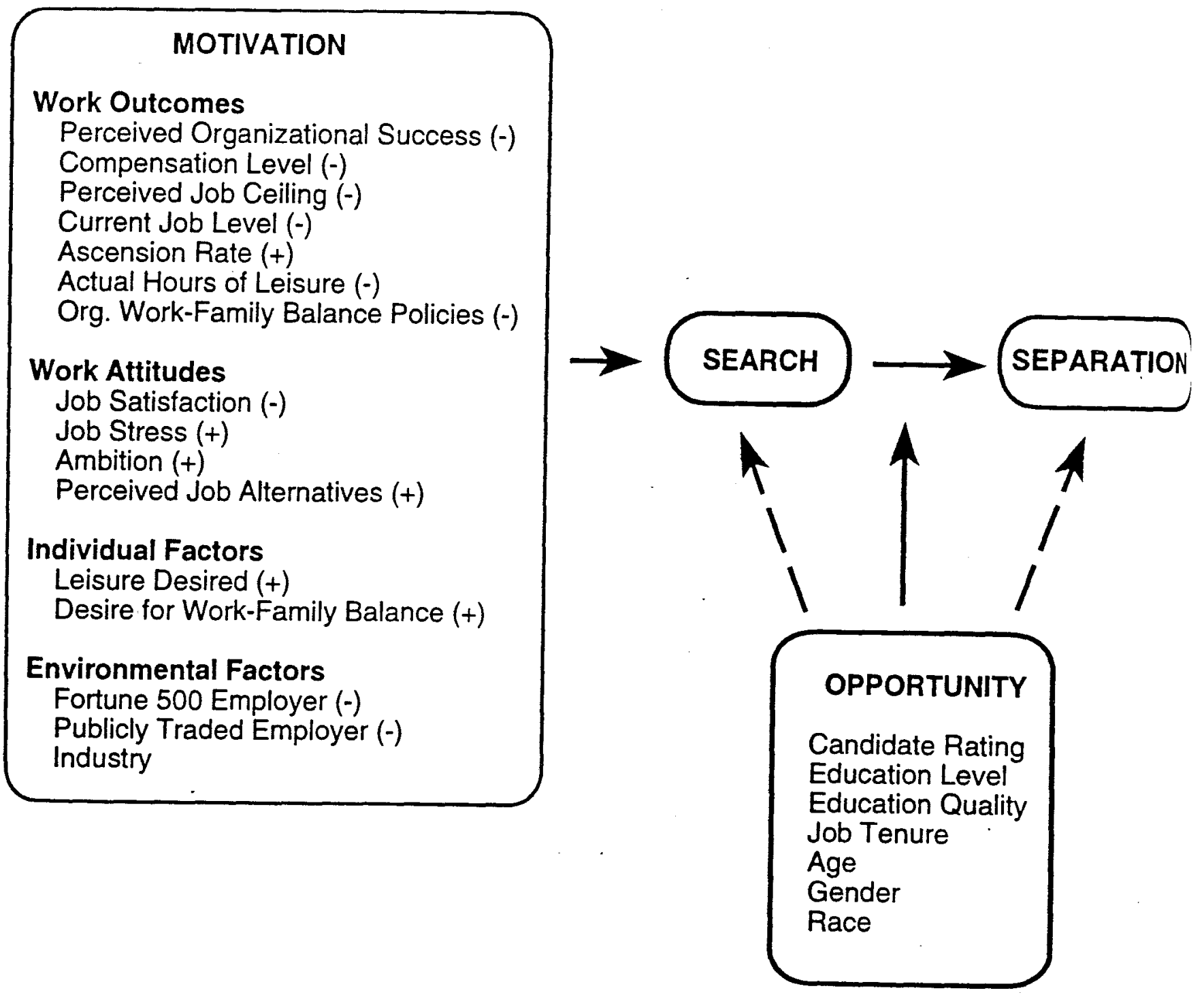




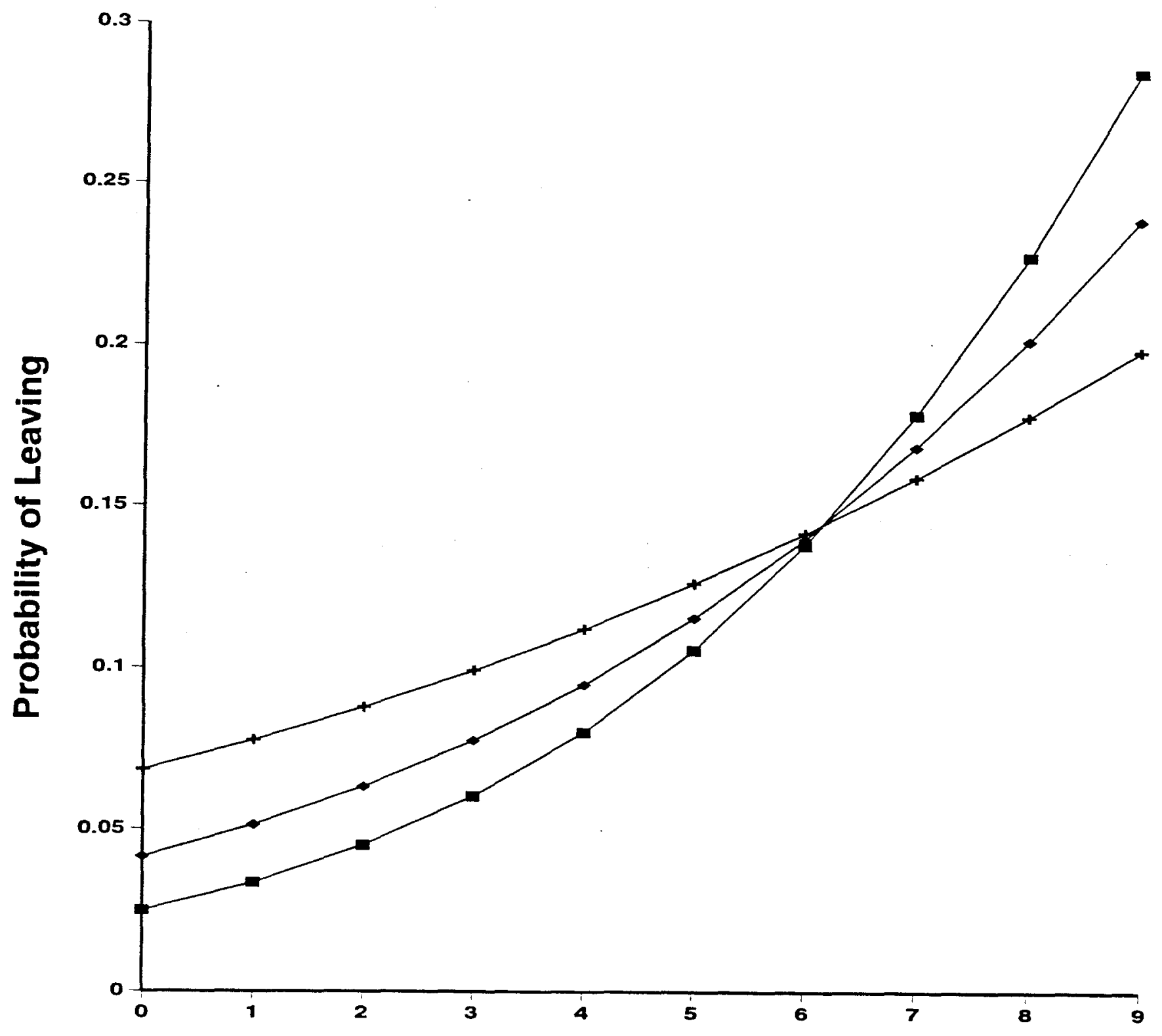

Search Activity

Notes. $\quad$ Education $=1.11(-1 S D)$

- Average Education Level $=1.72$

$+\quad$ Education $=2.33(+1 S D)$

Lines Cross at Search $=6.18 ;$ Probability of Leaving $=.145$ 